\title{
Doping esportivo e consumo de suplementos alimentares: uma relação delicada
}

Sports doping and dietary supplements consumption: a delicate relationship

Dopaje desportivo y consumo de suplementos alimenticios: uma relación delicada

José Carlos Loureiro da Silva ${ }^{1}$

Ana Carla Vasco de Toledo²

Marcelo Lamy3

\section{Resumo}

Objetivo: neste estudo, procura-se saber se os suplementos alimentares tão consumidos são aptos a causarem doping, já que os atletas buscam recursos ergogênicos visando à melhora da sua performance e, no campo nutricional, os suplementos aparecem como os mais consumidos. Metodologia: pesquisa bibliográfica descritiva, de abordagem exploratória; foram utilizadas informações oficiais de órgãos afetos ao controle de competições esportivas mundiais, bem como normas da Anvisa, agência reguladora brasileira. Resultados: verificou-se que a opção pelo alto consumo de suplementos alimentares se deve tanto à influência massiva da publicidade, que promete resultados miraculosos, quanto à facilidade de aquisição desses produtos. A eficácia de muitos deles carece de comprovação científica, enquanto outros podem causar efeitos colaterais graves pouco divulgados, além de conter substâncias de uso proibido e aptas a causar doping. No Brasil, a indústria de suplementos alimentares ganhou marco regulatório apenas em 2018, razão pela qual ainda não foi possível uma avaliação rigorosa dos seus efeitos. Conclusão: constatou-se que a multidisciplinariedade que envolve a relação entre dopagem e consumo de suplementos alimentares é a responsável pela dificuldade de controle do setor, reveladora ainda de quão movediça é a abordagem do problema no qual, frequentemente, se imiscuem novas áreas de conhecimento, exigindo profundo saber interdisciplinar. Daí a necessidade da interferência de profissionais habilitados para a prescrição de tais suplementos somente nos casos em que eles se mostrem necessários.

\section{Palavras-chave}

Esporte. Nutrição. Doping. Suplementos alimentares.

\begin{abstract}
Objective: this study seeks to know if the massive consumed dietary supplements can cause doping, since, unable to accept their limits, athletes search ergogenic methods aiming for the increase of their performance and, in the nutritional field, dietary supplements appear as the most prominent choice. Methods: the present paper is a descriptive bibliographic research, with an exploratory approach, in which were used official information of organs related to the

\footnotetext{
${ }^{1}$ Pós-doutorando em Direito da Saúde, Universidade Santa Cecília (Unisanta), Santos, SP, Brasil; médico; promotor de Justiça aposentado, Ministério Público do Estado de São Paulo, São Paulo, SP, Brasil. https://orcid.org/0000-0002-62979862. E-mail: zeloureiro33@gmail.com

2 Doutora em Direito Ambiental Internacional, Universidade Católica de Santos (Unisantos), Santos, SP, Brasil; professora, Faculdade de Bertioga (FABE), Bertioga, SP, Brasil. https://orcid.org/0000-0003-2076-4529. E-mail: anacarla@alopias.com.br

${ }^{3}$ Doutor em Direito Constitucional, Pontifícia Universidade Católica (PUC), São Paulo, SP, Brasil; professor permanente e vice-coordenador, Programa de Pós-Graduação em Direito da Saúde, Universidade Santa Cecília (Unisanta), Santos, São Paulo, Brasil. http://orcid.org/0000-0001-8519-2280. E-mail: marcelolamy@unisanta.br
} 
control of world sports competitions, as well as Brazilian regulatory agency rules. Results: It was found that the option for the huge consumption of dietary supplements is due to the influence of massive publicity - that promises miraculous results - and to the ease of the purchase of these products. The effectiveness of many of them lack scientific proof; many others may cause serious side effects that are not disclosed, containing substances of prohibited use and able to characterize doping. In Brazil, the sector has reached a regulation mark only in 2018 , the reason why a rigorous evaluation of its effects was not possible to be done. Conclusions: it was found that the multidisciplinarity that concerns the relationship between doping and consumption of dietary supplements is responsible for the difficulty of controlling the sector, revealing how unstable is the approach to the problem, in which new areas of knowledge are often inserted, requiring deep interdisciplinary knowledge. Hence the need for the intervention of qualified professionals to prescribe such supplements only in cases where they are necessary.

\section{Keywords}

Sport. Nutrition. Doping. Dietary suplements.

\section{Resumen}

Objetivo: en este estudio se busca conocer si los complementos alimenticios que se consumen ampliamente son susceptibles de provocar dopaje, ya que los deportistas buscan recursos ergogénicos con el objetivo de mejorar su rendimiento y, en el ámbito nutricional, los complementos aparecen como los más consumidos. Metodología: investigación bibliográfica descriptiva, con enfoque exploratorio; Se utilizó información oficial de agencias relacionadas con el control de las competiciones deportivas mundiales, así como normas de Anvisa, la agencia reguladora brasileña. Resultados: se encontró que la opción por un alto consumo de complementos dietéticos se debe tanto a la influencia masiva de la publicidad, que promete resultados milagrosos, como a la facilidad de compra de estos productos. La eficacia de muchos de ellos carece de pruebas científicas, mientras que otros pueden provocar efectos secundarios graves y poco conocidos, además de contener sustancias de uso prohibido y aptas para causar dopaje. En Brasil, la industria de complementos alimenticios obtuvo un marco regulatorio recién en 2018, por lo que aún no ha sido posible evaluar rigurosamente sus efectos. Conclusión: se constató que la multidisciplinariedad que implica la relación entre el dopaje y el consumo de complementos alimenticios es responsable de la dificultad para controlar el sector, revelando además lo rápido que es el abordaje del problema, en el que muchas veces se imbuyen nuevas áreas de conocimiento. lo que requiere un profundo conocimiento interdisciplinario. De ahí la necesidad de la intervención de profesionales cualificados para prescribir dichos suplementos solo en los casos en que sean necesarios.

\section{Palabras clave}

Deporte. Nutrición. Dopaje. Suplementos alimenticios.

\section{Introdução}

A origem da palavra doping é controversa. Alguns estudiosos afirmam ser ela proveniente de doop, vocábulo de dialeto africano que designa certa infusão estimulante usada em cerimônias religiosas (1). Outros autores asseguram que o termo provém do holandês dopen, que significa emergir ou batizar, tendo sido utilizado na Holanda com o significado de dopagem em torno de 1865, época da construção do Canal do Norte, que liga 
Amsterdam ao mar. Nessa ocasião, certos construtores fluviais ministravam uma substância aos seus empregados de construção naval, que tinha a finalidade de torná-los mais resistentes, conseguindo, assim, que permanecessem mais tempo na água, havendo maior rendimento no trabalho (2).

Os bures ${ }^{4}$ levaram o termo para a Inglaterra, onde passou a designar a prática de estimular cavalos com álcool, vindo a surgir, pioneiramente, em um dicionário inglês em 1889, significando certa mistura de narcóticos e ópio usada em equídeos (3). Posteriormente, esse conceito foi estendido a todo produto apto a causar estimulação ${ }^{5}(4)$.

Interessante a observação de Tihamér Zilizi Csáky (5) de que o primeiro caso de doping teria ocorrido no Paraíso, já que a Bíblia descreve que Adão e Eva comeram o fruto proibido porque a serpente lhes disse que, se assim procedessem, ficariam tão fortes e poderosos quanto Deus (5). Constata-se, portanto, que esse doping pioneiro pode ser considerado de caráter nutricional.

O certo é que, inconformados com os seus próprios limites, os homens sempre estiveram à procura de substâncias que proporcionassem melhora do seu desempenho. A história se encontra repleta de fatos que evidenciam essa eterna busca por resultados a qualquer preço, não constituindo novidade ou prática específica da contemporaneidade.

No âmbito desportivo - foco do presente estudo -, já se afirmou que a utilização de doping é quase tão antiga quanto à existência dos esportes (6). Nesse tema, a primeira referência bibliográfica disponível data de 2737 a.C., época na qual Shen-Nunge, imperador da China, descreveu o efeito estimulante de uma planta denominada machuang, que era utilizada pelos atletas do seu país (7). Ainda na Antiguidade, no século III a. C., Galeno e Filostrato relataram que os atletas gregos procuravam aumentar o seu desempenho nos Jogos Olímpicos ingerindo substâncias como cogumelos, ervas, testículos de touro, dentre outras (8). Constata-se, portanto, que na história das Olimpíadas, desde os seus primórdios, não é somente o decantado espírito olímpico que prevalece, havendo interesses concomitantes relativos a nacionalismos, pressão de patrocinadores, dinheiro, poder etc., e, consequentemente, a ocorrência de fraudes e doping.

\footnotetext{
${ }^{4}$ Bures é pronúncia de bôeres (de boer, que em holandês significa camponês e se pronuncia bur), também denominados africâners, que são os descendentes dos holandeses e franceses instalados no século XVII na região do Cabo da Boa Esperança.

${ }^{5}$ Eduardo Henrique De Rose, em trabalho sobre anabólicos esteroides e suas repercussões na saúde, apresenta para o vocábulo significado idêntico ao do Fernando Vitor Lima, porém assegura que a palavra original provém do africâner dop.
} 
O objetivo do presente estudo é demonstrar que os suplementos alimentares podem causar efeitos colaterais e, se consumidos por atletas, podem ocasionar doping. Tais substâncias carecem de estudos que comprovem a sua eficácia, fazendo-se críticas tanto à publicidade massiva desses produtos quanto à facilidade na aquisição dos mesmos.

\section{Metodologia}

A abordagem da investigação foi essencialmente exploratória, ancorada na coleta qualitativa de três ordens de materiais: bibliográfico; de informações oficiais dos órgãos afetos ao controle de competições esportivas mundiais, como o Comitê Olímpico Internacional (COI) e a World Anti-Doping Agency (WADA); e ainda de normas de agência reguladora brasileira, a Agência Nacional de Vigilância Sanitária (Anvisa). A análise, tendo em vista o perfil exploratório e a base qualitativa, seguiu a lógica da revisão narrativa e integrativa, de perfis metodológicos mais elásticos.

\section{O doping na era moderna}

Thomas Hicks é apontado como protagonista do primeiro caso de dopagem dos tempos modernos, ocorrido nos Jogos Olímpicos de Saint Louis, Estados Unidos, em 1904 (8). Hicks cansou-se durante a maratona e a sua equipe de apoio Ihe ministrou conhaque e, por duas vezes, estricnina. Essa substância constitui um poderoso estimulante dos neurônios motores, aqueles que controlam as contrações musculares. O atleta se recuperou, venceu a prova, mas desmaiou logo em seguida. Sabe-se que doses pequenas de estricnina são suficientes para causar convulsões e morte do usuário por paralisia dos músculos respiratórios. Apesar de o fato haver sido descoberto, Hicks manteve a medalha porque nem a estricnina e nem o conhaque eram substâncias proibidas no âmbito desportivo àquela época (9).

Apesar da ocorrência pioneira de doping em 1904, foi somente em 1938 que o COI resolveu, pela primeira vez, condenar a utilização de produtos dopantes. Porém, como não existiam controles antidopagem, restou ser proibição de aspecto meramente retórico, em que pese o aparecimento de certas medidas de controle, tal como a inspeção dos vestuários visando a busca de provas e vestígios de uso (10).

A Olimpíada de 1952, realizada em Helsinque, na Finlândia, foi a primeira a contar com a participação da União das Repúblicas Socialistas Soviéticas (URSS), e o excepcional desempenho dos seus atletas na modalidade de levantamento de peso suscitou suspeitas 


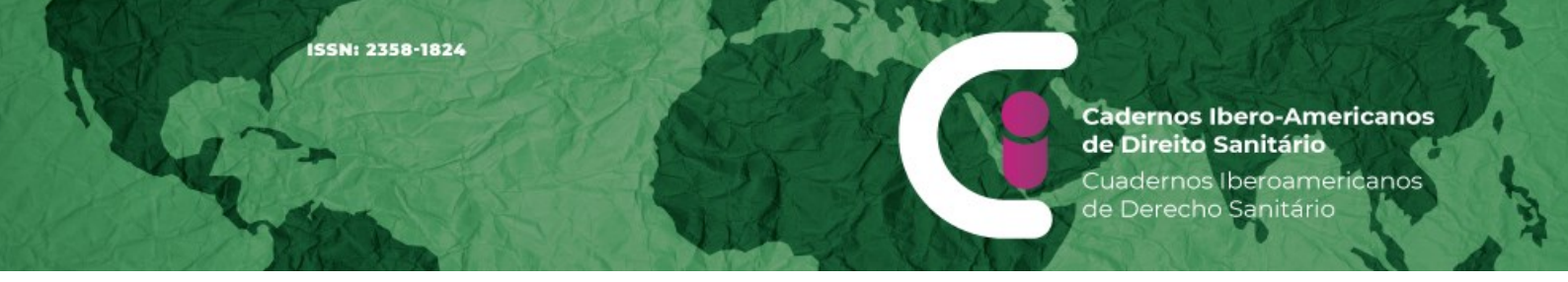

de que estariam dopados (11). O fato foi confirmado durante a Olimpíada de Melbourne, de 1956, quando o médico norte-americano John Bosley Ziegler, membro da equipe médica dos Jogos, constatou que competidores soviéticos utilizaram cateteres urinários. Isso se devia ao fato deles haverem usado testosterona, substância que, ao lado de melhorar a performance do atleta, causa dilatação da próstata a ponto de obstruir a uretra e impedir o seu usuário de urinar. Ao retornar aos Estados Unidos, Ziegler informou à comunidade médica e esportiva sobre o uso de esteroides pelos soviéticos. Visando à diminuição dos efeitos colaterais da testosterona (12), o médico assessorou a companhia farmacêutica CIBA

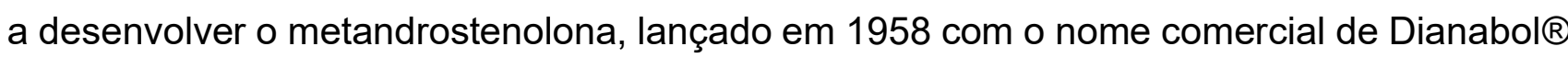
(13), considerado o primeiro grande esteroide anabólico-androgênico, que foi muito usado pelos atletas norte-americanos (14).

Um caso dramático de doping ocorreu em 1960, nas Olimpíadas de Roma, quando o ciclista dinamarquês Knut Enemark Jensen se desequilibrou durante a corrida e caiu da bicicleta, batendo a cabeça numa pedra, falecendo antes mesmo de ser levado a um hospital (15). A causa mortis apontada pelo médico foi hemorragia cerebral provocada por insolação, justificada pelo fato de o ciclista não estar usando capacete no momento do acidente, sob o intenso sol do verão romano. Alguns dias depois o treinador de Jensen confessou, diante de uma comissão de investigação da Federação de Ciclismo, que havia ministrado ao atleta uma dose de Ronicol®, fármaco ativador da circulação sanguínea. Constatou-se, ademais, que outros dois ciclistas da Dinamarca não haviam terminado a prova por terem passado mal devido ao uso da mesma droga. Investigação ulterior apurou que a utilização desse remédio era prática disseminada entre profissionais da modalidade e que a dopagem era comum entre os atletas amadores, mas havia sido essa a primeira vez que um caso concreto era descoberto e revelado (6).

O COI restou abalado pela tragédia causada por esse doping, mas o presidente da instituição, à época, Avery Brundage, mais preocupado com o mercantilismo olímpico e a profissionalização dos atletas, não dispensou maior atenção ao problema. Coube à Federação Internacional de Ciclismo o pioneirismo de controlar o doping nas suas competições (6).

Porém, o COI não podia mais manter-se indiferente ao problema e viu-se obrigado a tomar providências mais rígidas, visando a coibir o uso de substâncias aptas a dopar, concluindo que o mais apropriado seria começar a realizar controles de dopagem. O Comitê criou então, em 1961, uma junta médica, considerada a semente da atual Comissão Médica 
dessa instituição. Somente em 1967 o COI estabeleceu, de maneira oficial, a realização dos controles antidopagem, bem como a punição daqueles atletas cujos exames resultassem positivos. A Comissão iniciou tais controles em amostras de urina dos atletas durante os Jogos Olímpicos de Inverno em Grenoble, em 1968 (10), atuando ainda, nesse mesmo ano, nos Jogos Olímpicos de Verão, no México (16).

Para essas duas competições a Comissão publicou a primeira lista de substâncias taxadas como proibidas. Devido ao fato de a cada edição dos Jogos Olímpicos surgirem novas técnicas no setor da dopagem, a Comissão Médica do COI foi obrigada a alterar constantemente a lista de métodos e classes farmacológicas proibidas, prática que permanece até os dias atuais. É publicada uma nova lista, sempre no dia $1^{\circ}$ de janeiro de cada ano, com a aprovação e o endosso da Agência Mundial Antidoping (AMA) (17) - World Anti-Doping Agency (WADA), em inglês -, instituição que estabelece regras e diretrizes para o combate à dopagem em escala mundial, politicamente expandidas pela Organização das Nações Unidas para a Educação, a Ciência e a Cultura (Unesco) e outros órgãos (18).

\section{Do conceito de doping}

Alaor Leite (19) assegura que não há consenso sobre o conceito de doping, mesmo se consultando compêndios médicos, livros de nutrição, tratados de ética desportiva ou regulamentos jurídicos. Cyril Petibois (20) faz advertência em idêntico sentido, lembrando que, no esporte, a definição de doping está longe de ser explícita. Isso deixa evidente a dificuldade no trato da temática, haja vista, entre outros, que a própria lista de produtos e métodos proibidos no esporte se altera anualmente. O estudo do assunto é movediço, já que frequentemente, por conta dos avanços tecnológicos, estão a surgir novas áreas de conhecimento envolvidas na questão, requerendo elevado saber interdisciplinar aos pesquisadores do doping desportivo (21).

A AMA define doping como a ocorrência de uma ou mais violações às regras antidopings estabelecidas do Artigo 2.1 ao Artigo 2.10 do Código Mundial Antidoping (22). O Código trata-se de um documento central que concilia políticas, regras e regulamentos antidoping dentro de organizações esportivas e entre autoridades públicas em todo o mundo. Reúne, em abordagem unificada, problemas que foram constatados por pesquisas antidopagem por vezes descoordenadas e desarticuladas (22) constituindo documento-base para todas as agências esportivas que seguem as orientações estabelecidas pela AMA, renovado a cada cinco anos, sendo de 2015 a sua última versão (18). Pelo critério do Código, 
ocorre dopagem quando é encontrada substância proibida em um atleta; quando terceiro administra substância ou utiliza método proibido em um competidor; quando o competido se nega a se submeter a um exame antidoping; quando uma pessoa trafica substância ou método proibido para o meio desportivo; quando alguém manipula o controle antidopagem (22).

Para a Federação Internacional de Medicina Esportiva, o "Doping no esporte é o uso por um atleta, de forma deliberada ou não, de uma substância ou método banido pelo Comitê Olímpico Internacional" (23). Ressalte-se que o doping não se limita apenas à utilização de substâncias condenadas na área esportiva, como diuréticos, esteroides anabolizantes, hormônio do crescimento $(\mathrm{GH})$, abrangendo, ainda, uma série de técnicas, entre as quais transfusão ou autotransfusão de sangue.

Curioso destacar que muitas substâncias e procedimentos não são socialmente ilegais ou proibidas, o que se veta é a sua utilização no esporte por ocasionarem vantagens aos seus usuários em competições. Certas drogas foram, inicialmente, desenvolvidas para debelar doenças e, hoje, auxiliam milhões de pessoas a ter uma vida mais saudável, mas proíbe-se o seu uso para fins desportivos. Como exemplo são citados os esteroides anabólicos, empregados para prevenir má nutrição em pacientes cancerosos e aidéticos, em casos de deficiência de testosterona e no tratamento de osteoporose, assim como os beta2-agonistas, utilizados para o tratamento de crises de asma (11).

\section{Alimentação e esporte}

O liame entre alimentação e desempenho esportivo é conhecido desde a Grécia e Roma antigas, havendo relatos de alimentos específicos e dietas especiais usados por atletas gregos já em 580 a.C. (24). Charmis de Esparta foi o primeiro competidor sobre o qual há referências de submissão a um regime alimentar específico, à base de figos secos, tendo sido vencedor dos 200 metros rasos nos Jogos Olímpicos de 668 a.C., e a tradição parece indicar que, como velocista, ele encontrou açúcar extra na fruta que consumia (25).

O certo é que a alimentação adequada tem sido relacionada a um melhor desempenho esportivo, e excetuando o treino para melhoria do rendimento físico associado aos limites impostos pela hereditariedade, nenhum outro fator tem influência tão relevante na performance esportiva como a nutrição (26). Na prática, não é difícil perceber que adeptos de exercícios físicos e atletas em geral procuram recursos ergogênicos visando melhorar seu desempenho, sendo que no setor da nutrição o consumo de suplementos alimentares 
surge como opção de maior destaque. Essa busca constitui prática antiga, havendo registros que, no período entre 400 e 500 a. C., atletas já manipulavam alimentos visando a melhora de rendimento esportivo (27), tendo sido os alemães, em 1842, os precursores dos estudos científicos nesse setor (28). Mas, afinal, o que são esses suplementos?

Suplementos alimentares ou nutricionais são produtos compostos por fontes concentradas de determinadas substâncias como vitaminas, proteínas, minerais, aminoácidos, fibras, ácidos graxos, ervas e extratos, probióticos, além de enzimas, aminoácidos, fitoesteróis, carotenoides, entre outras. Podem apresentar efeitos nutricionais, metabólicos e/ou fisiológicos destinados a complementar a alimentação normal nos casos em que a ingesta de certos componentes seja insatisfatória. Apresentam-se nas formas sólida, semissólida, líquida e aerossol, como tabletes, granulados, pastilhas mastigáveis, drágeas, pós, cápsulas, líquidos e suspensões (29). Válido salientar que suplementos alimentares não são medicamentos, portanto não se prestam a curar, tratar ou prevenir doenças, sendo destinados a indivíduos saudáveis. A finalidade dos mesmos é o fornecimento de substâncias bioativas, nutrientes, probióticos ou enzimas como complemento à alimentação (30).

Uma dieta composta de alimentos variados e em quantidades corretas é apta a fornecer todos os nutrientes necessários ao corpo humano (31). Porém, a influência exercida pelo marketing da indústria de suplementos nutricionais sobre atletas e profissionais de desportos fez gerar a crença de que tais suplementos são essenciais para um ótimo desempenho esportivo (32). As promessas são as mais variadas: aumento de resistência, redução do risco de doenças, melhora na recuperação, aumento da massa magra e diminuição da massa gorda etc., apelos aos quais os atletas são particularmente sensíveis, o que os transforma em público-alvo relevante para a milionária indústria de suplementos alimentares (33). Some-se a isso o fato de organizações desportivas, bem como equipes e atletas, serem frequentemente patrocinados por empresas fabricantes desses suplementos, cujo número no mercado mundial vai além de 75 mil empresas e cresce dia a dia (34).

Financial Times informou que, em 2001, a indústria de suplementos alimentares já investia globalmente 46 bilhões de dólares em publicidade como forma de convencer potenciais consumidores a adquirir seus produtos (31). Somente no Brasil, de acordo com a Associação Brasileira dos Fabricantes de Suplementos Nutricionais e Alimentos para Fins Especiais (Brasnutri), entre 2010 e 2016, o faturamento do mercado desses produtos passou de R\$ 


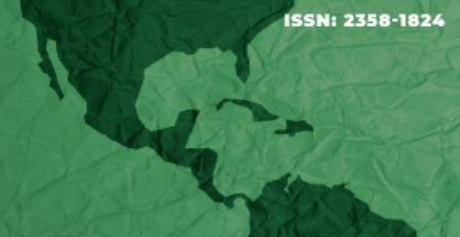

637 milhões para $\mathrm{R} \$ 1,49$ bilhão, colocando o país como o terceiro maior consumidor de suplementos alimentares do mundo, depois dos Estados Unidos e da Austrália (35).

Apesar da exuberância desse mercado, até há pouco tempo não era ele devidamente normatizado no Brasil. Somente em julho de 2018 é que a Anvisa publicou resoluções visando a regrar o setor.

O novo marco regulatório dos suplementos alimentares no Brasil

Apesar de comercialmente relevantes e representativos de um mercado milionário e em constante ascensão, até recentemente não havia, no Brasil, definição jurídica precisa acerca da natureza dos suplementos nutricionais, nem tratamento regulatório específico pelas entidades competentes. Até então a Anvisa incluía os suplementos alimentares em outras categorias já existentes, tais como alimentos para atletas e suplementos minerais e vitamínicos.

Em 27 de julho de 2018 a Anvisa publicou novas regras para a produção e distribuição de suplementos alimentares. Produtos como complexos vitamínicos, itens à base de proteína (como creatina, termogênicos e o popular whey protein) ou cápsulas de óleo de peixe se encontram agora reunidos sob uma mesma categoria e resumidos a suplementos. Interessante observar que, antes da aprovação e publicação dessas normas, caso esses produtos incluíssem em seus rótulos a informação suplemento alimentar, as empresas produtoras estariam cometendo uma infração sanitária, consoante a Anvisa advertia em seu site. Agora, pelo contrário, essa informação deverá constar nos rótulos e de maneira legível (36).

O novo marco legal voltado aos suplementos alimentares é composto por seis normas, sendo cinco resoluções da diretoria colegiada (RDCs) e uma instrução normativa (IN) (Quadro 1). 
Quadro 1. Normas sobre suplementos alimentares no Brasil

\begin{tabular}{|c|c|}
\hline Normas & Ementas \\
\hline RDC 239/2018 & $\begin{array}{l}\text { Estabelece os aditivos alimentares e coadjuvantes de tecnologia autorizados } \\
\text { para uso em suplementos alimentares. }\end{array}$ \\
\hline RDC 240/2018 & $\begin{array}{l}\text { Categorias de alimentos e embalagens isentos e com obrigatoriedade de } \\
\text { registro sanitário. } \\
\text { Altera a RDC } n^{\circ} 27 \text {, de } 6 \text { de agosto de } 2010 .\end{array}$ \\
\hline RDC 241/2018 & $\begin{array}{l}\text { Dispõe sobre os requisitos para comprovação da segurança e dos benefícios à } \\
\text { saúde dos probióticos para uso em alimentos. }\end{array}$ \\
\hline RDC 242/2018 & $\begin{array}{l}\text { Regulamenta o registro de vitaminas, minerais, aminoácidos e proteínas de uso } \\
\text { oral, classificados como medicamentos específicos. } \\
\text { Altera a RDC } n^{\circ} 24 \text {, de } 14 \text { de junho de } 2011 \text {, a RDC } n^{\circ} 107 \text {, de } 5 \text { de setembro } \\
\text { de } 2016 \text {, a IN } n^{\circ} 11 \text {, de } 29 \text { de setembro de } 2016 \text { e a RCD } n^{\circ} 71 \text {, de } 22 \text { de } \\
\text { dezembro de } 2009 \text {. }\end{array}$ \\
\hline RDC 243/2018 & Dispões sobre os requisitos sanitários dos suplementos alimentares. \\
\hline IN 28/2018 & $\begin{array}{l}\text { Estabelece as listas de constituintes, de limites de uso, de alegações e de } \\
\text { rotulagem complementar dos suplementos alimentares. }\end{array}$ \\
\hline
\end{tabular}

Fonte: Anvisa (37).

Os regramentos específicos dos suplementos alimentares são a RDC n² 243/2018, a IN $n^{\circ} 28 / 2018$ e a RDC $n^{\circ} 239 / 2018$, como se constata pela dicção das suas ementas. A RDC n $n^{\circ} 243 / 2018$ no seu art. 3, inc. VII, finalmente introduziu um conceito legal preciso de suplemento alimentar ao dispor que se trata de "produto para ingestão oral, apresentado em formas farmacêuticas, destinado a suplementar a alimentação de indivíduos saudáveis com nutrientes, substâncias bioativas, enzimas ou probióticos, isolados ou combinados" (38). O novo regramento convencionou que as listas da IN n $28 / 2018$ poderão ser periodicamente atualizadas, desde que se comprove a eficácia e a segurança dos respectivos constituintes (39).

De acordo com a Anvisa, o objetivo dessa modernização normativa é garantir a segurança dos consumidores, a qualidade dos suplementos, aliando a diminuição dos empecilhos à comercialização, o esmero no controle sanitário e a inovação do setor (40). Para atingir esse objetivo, foram feitas várias alterações na legislação sanitária, que propiciaram um delineamento regulatório mais compreensível e proporcional ao risco dessas substâncias, inserindo a modernização dos requisitos sanitários com base em evidências científicas. A regulamentação novel traz definições, requisitos para atualização das listas de constituintes, regras de composição, qualidade, segurança e rotulagem e limites de uso, 
além de rotulagem complementar. As normas foram elaboradas de forma a comportarem inovações e assegurarem que esses produtos atendam aos ditames legais de alimentos $(41)$.

Pelo novo regramento, para que um produto seja identificado como suplemento alimentar, na sua embalagem deverá constar a expressão suplemento alimentar em negrito e caixa alta, seguida da forma farmacêutica da apresentação do produto. Pode haver acréscimo de outras informações de relevância para o consumidor, como aquilo que o suplemento fornece - nome individual ou categoria do nutriente, da enzima e da substância bioativa -, bem como a fonte de onde se extraiu a substância (41).

Com as novas normas, já não mais se poderá prometer certos efeitos positivos, que para a Anvisa são vistos como alegações funcionais. Foram listadas 189 alegações funcionais permitidas e as demais, além de não serem mais aceitas, serão passíveis de punições. Com isso, a Anvisa impede que indivíduos sejam ludibriados com a promessa de resultados miraculosos pelo uso desses suplementos (42).

Constata-se a preocupação dessas novas normas em relação ao doping, quando se depara com a RDC n² 243/2018, que dispõe expressamente: “Art. $7^{\circ}$ Não são permitidos na composição de suplementos alimentares: I - substâncias consideradas como doping pela Agência Mundial Antidopagem". Isso se deve, entre outras razões, ao fato de a publicidade desses suplementos ser intensa, sendo apresentados como produtos que só trazem benefícios. Entretanto, em muitos casos, eles não são inócuos.

\section{Consumo de suplementos alimentares e doping}

A utilização de suplementos nutricionais constitui motivo de preocupação devido ao fato de inexistir comprovação científica da eficácia de muitos deles (43). Ocorre que o método recomendado para uma melhor investigação dos efeitos de suplementos no desempenho dos atletas é o estudo clínico prospectivo, randomizado 6 e controlado, duplo cego, ${ }^{7}$ sob condições padronizadas que, preferencialmente, simulem o dia a dia de um atleta. Infelizmente, não é desta modalidade de pesquisa que provém a maioria das informações sobre a eficácia dos suplementos alimentares na atividade esportiva, mas sim

\footnotetext{
${ }^{6}$ Essa expressão provém do inglês random, que significa aleatório. É utilizada em pesquisas nas quais a escolha de pessoas que usarão a droga testada ou o produto placebo é feita ao acaso, de forma aleatória, procurando evitar qualquer tipo de favorecimento induzido pelas expectativas do pesquisador. (Nota dos autores).

${ }^{7}$ Estudo duplo-cego ou ensaio clínico em dupla ocultação constitui método de pesquisa realizado em seres humanos onde nem o examinado e nem o pesquisador sabem o que está sendo usado como variável em certo momento. (Nota dos autores).
} 


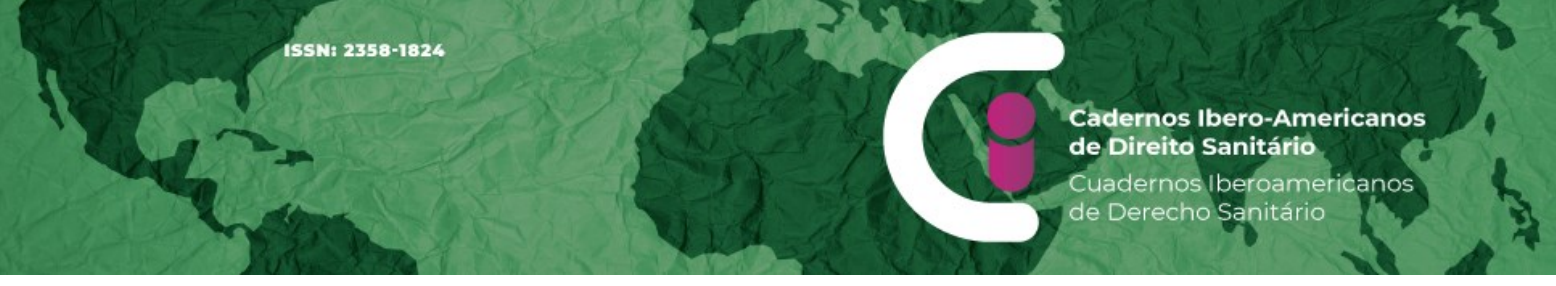

Em suplementos alimentares, rotulados como não hormonais, análises de laboratório revelaram a presença de substâncias vetadas pela listagem da WADA (Quadro 3).

Quadro 3. Incidência de substâncias proibidas pela WADA em suplementos nutricionais rotulados como não hormonais de dezembro de 2002 a agosto de 2005

\begin{tabular}{|l|l|}
\hline \multicolumn{1}{|c|}{ Substância encontrada } & \multicolumn{1}{c|}{ Quantidade } \\
\hline e-hidroepiandrosterona & 27 \\
\hline Testosterona & 18 \\
\hline 4-Androsteno-3, 17-diona & 16 \\
\hline 19-Nor-4-Androsteno-3, 17-diona & 9 \\
\hline Di-hidrotestosterona & 8 \\
\hline Nandrolona & 5 \\
\hline 5-Androsteno-3 $\beta, 17 \beta-d i o l$ & 5 \\
\hline 17a-Metiltestosterona & 2 \\
\hline
\end{tabular}

Fonte: Laboratório de Controle de Doping de Ghent (Bélgica), acreditado pela WADA (46).

Alegar que ingeriu suplemento alimentar mal rotulado, desconhecendo a sua verdadeira composição, não constitui defesa adequada para a acusação de dopagem, motivo pelo qual muitos atletas profissionais têm as carreiras arruinadas em razão de um simples descuido ou escolha equivocada de um desses produtos. A Agência Mundial Antidoping orienta as entidades esportivas a aplicarem punições rigorosas aos atletas flagrados em exames de detecção, restando aos infratores pequena margem para defesa. Isso ocorre porque o Código Mundial Antidoping (CMAD) adota o princípio denominado Strict Liability Rule, ou Princípio da Responsabilidade Objetiva, derivado da common law, responsabilidade essa que independe de dolo ou culpa (47). Ou seja, se a substância proibida (ou seus metabólitos, ou marcadores) for encontrada em amostra corporal do atleta, ele responderá pela infração, não importando a maneira pela qual o produto foi parar em seu organismo (22).

Além do atleta, a responsabilidade pelo doping pode ser dos médicos, técnicos e do staff de apoio. A responsabilização desses profissionais constitui uma nova determinação da WADA e das Federações Internacionais, entendendo ser dever de toda a equipe técnica zelar pelo bem-estar de seus competidores. Em caso de o atleta adoecer, cabe 
prioritariamente aos médicos esclarecê-lo com relação às substâncias a serem usadas em seu tratamento. Se inexistente outra opção de medicamento senão aquele que contenha substância proibida no meio desportivo, deve o médico recomendar que o atleta se afaste de competições por um espaço temporal suficiente à saída daquele produto do seu organismo (47).

Ressalte-se que, além de poderem causar danos à carreira de atletas devido ao doping, os suplementos alimentares também são capazes de produzir malefícios em seus organismos, efeitos colaterais pouco divulgados, já que nessa área, como assevera o professor e doutor em educação física Aylton Figueira Jr, escasseia informação e sobra publicidade (48). Na década de 1980, no Japão, foi relatada uma dezena de mortes após o consumo de um suplemento alimentar à base de triptofano, um aminoácido (49). Acerca dessa mesma questão, o médico Drauzio Varella afirma que todos os sete suplementos mais comuns no mercado são capazes de causar prejuízos ao organismo do usuário. Os chamados pré-treinos podem causar ansiedade, tremores e dependência. Os termogênicos podem produzir enjoo, agressividade e cefaleia no atleta (50), havendo registro, no Brasil, em 2016, de uma jovem de 23 anos que morreu de infarto após consumir essa modalidade de suplemento e se exercitar, tendo feito isso por vários dias (51). Os aminoácidos podem motivar flatulência e constipação. As proteínas podem fazer o usuário engordar, ter desconforto gastrointestinal e flatulência. A creatina pode provocar retenção hídrica, os carboidratos propiciam o surgimento de acne e os suplementos hormonais podem causar disfunção hepática e renal, podendo ocorrer, nas mulheres, aumento de pelos e do clitóris, alteração no ciclo menstrual e calvície, enquanto os homens podem desenvolver ginecomastia, hipogonadismo e impotência sexual (50).

Constata-se, portanto, que, diversamente do que asseguram muitos anúncios quanto à inocuidade dos suplementos alimentares, estes produtos têm, sim, potencial de causar doping, além de outros malefícios ao organismo do atleta.

\section{Considerações finais}

A busca do homem pela superação dos seus próprios limites por meio da utilização de produtos ergogênicos acontece desde os primórdios da humanidade. Contemporaneamente, essa busca está levando a um exagerado consumo de suplementos alimentares especialmente pelos atletas, opção atraente pelo fato de nada ser exigido para a sua aquisição e estarem eles disponíveis em todo o mundo. 
Acontece que esses produtos podem ser benéficos para um número reduzido de indivíduos, aí incluídos desportistas cujas dietas não estejam sendo devidamente balanceadas. Somente quando comprovado que certo nutriente se encontra abaixo do seu índice normal no organismo da pessoa é que o aumento da sua ingestão é indicado por meio de suplementos alimentares, nos casos de inexistência de possibilidade da reposição ser feita por meio da alimentação habitual. Caso o nível do nutriente esteja normal, a ingesta do suplemento não trará qualquer benefício, podendo, em alguns casos, produzir efeitos colaterais.

Esses suplementos são produtos da moda, vendidos em qualquer lugar, adquiridos sem receita médica e sobre os quais a cotidiana e massiva publicidade, feita por celebridades, só aponta benefícios. Acontece que muitos achados da ciência acerca dos mesmos não é do agrado da indústria que os produzem. A verdade é que os suplementos alimentares têm, sim, potencial para causar doping nos atletas e poderem gerar enormes prejuízos no organismo dos indivíduos que os utilizam sem a devida orientação.

O fato de existirem variados tipos de suplementos, cada qual com a sua respectiva função, exige que tais produtos sejam consumidos apenas com orientação nutricional individualizada. Daí a necessidade da interferência do médico ou nutricionista, únicos profissionais aptos a fornecerem esse tipo de orientação.

Já se discorreu sobre os graves prejuízos que o consumo inadequado desses produtos possa trazer aos seus usuários, razão pela qual, apesar de se considerar um marco positivo a nova regulamentação brasileira acerca dos suplementos alimentares, lamenta-se que esses produtos continuem a ser vendidos sem a necessidade de prescrição de profissional habilitado. Por esse motivo os autores do presente estudo defendem que a Anvisa deva acrescentar essa exigência ao novel regramento. Evitar-se-ia, assim, a ocorrência de doping, que pode destruir carreiras de atletas promissores, bem como efeitos colaterais, que podem culminar até em óbito, decorrentes do uso inadequado de tais suplementos.

\section{Referências}

1. Lima FV. Doping no Esporte. In: Garcia ES, Lemos KLM, organizadores. Temas atuais V: em educação física e esportes. Belo Horizonte: Health; 2000. p. 131.

2. Gomes Jr GS. Dopagem: atleta dopado. Revista de educação física. 1964;1(5):26-27. 


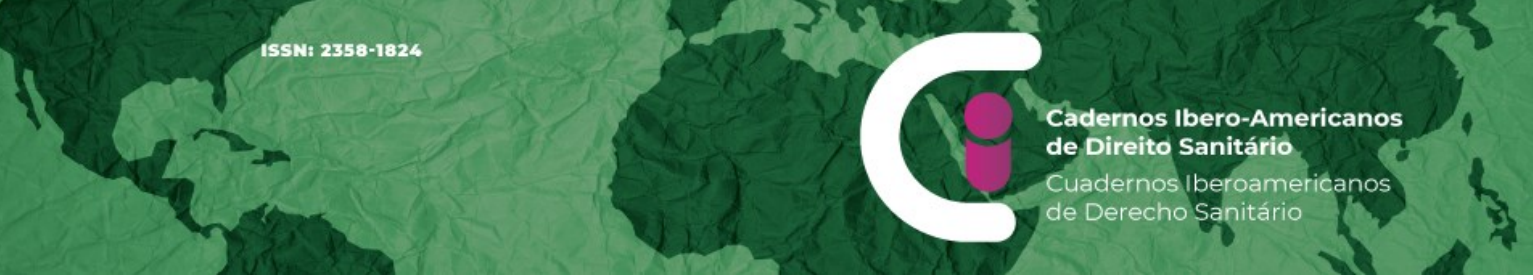

3. Weineck J. Biologia do esporte. $6^{\mathrm{a}}$ ed. Barueri: Manole; 1991.

4. Quintas GGS, coordenador. Valores humanos, corpo e prevenção: a procura de novos paradigmas para a educação física. Brasília: Ministério da Educação; 1989. p. 83.

5. Csáky TZ. Doping. The journal of sports medicine and phisical fitness. Europe: PCM; 1972. p 117-23.

6. Cardoso M. 100 anos de olimpíadas. De Atenas a Atlanta. São Paulo: Scritta; 1996

7. De Rose EH. O Uso de anabólicos esteroides e suas repercussões na saúde. In: Quintas, G. Valores humanos. Corpo e prevenção: a procura de novos paradigmas para a educação física. Brasília: Ministério da Educação; 1989. p. 83.

8. Weineck J. Biologia do esporte. $7^{\text {a }}$ ed. Barueri: Manole; 2005. p. 582.

9. Harkup K. The cocktail of poison and brandy that led to olympic gold. The Guardian [Internet]. 21 jul 2016 [acesso em 15.ago.2019]. Disponível em:

https://www.theguardian.com/ science/blog/2016/jul/21/the-cocktail-of-poison-and-brandythat-led-to-olympic-gold-strychnine

10. Tavares O, Romera L. Atividades físicas e esportivas e a dopagem. Movimento é vida: atividades físicas e esportivas para todas as pessoas [Internet]. Relatório Nacional de Desenvolvimento Humano do Brasil. 2017 [acesso em 17.ago.2019]. Disponível em: http://movimentoevida.org/wp-content/uploads/ 2017/09/Atividades-Fi\%CC\%81sicas-eEsportivas-e-Dopagem.pdf

11. Almeida MB, Gutierrez DM, Gutierrez GL. O doping e os Jogos Olímpicos: diferentes dimensões do fenômeno. Revista USP. 2016, jan./mar;108:77-86.

12. Waddington I. A história recente sobre o uso de drogas nos esportes: a caminho de uma compreensão sociológica. In: Gebara A, Pilatti LA, coordenadores. Ensaios sobre história e sociologia nos esportes. Jundiaí: Fontoura; 2006. p. 13-44

13. Peters J. The man behind the juice. Slate [Internet]. 18 fev 2005 [acesso em 26.jul.2020]. Disponível em: https://slate.com/culture/2005/02/the-doctor-who-broughtsteroids-to-america.html

14. Waddington I. Strict liability in anti-doping. Wada [Internet]. [s.d.] [acesso em 26.jul.2020]. p.19. Disponível em: https://www.wada-ama.org/en/questions-answers/strictliability-in-anti-doping\#item-720

15. Betting D, Rigue A. Morte de ciclista em 1960 trouxe ao mundo o doping nos Jogos Olímpicos. UOL. 27 jun 2016 [acesso em 20.jul.2020]. Disponível em:

https://esporte.band.uol.com.br/rio-2016/noticia/100000812139/morte-de-ciclista-em-1960trouxe-ao-mundo-o-doping.html

16. Müller RK. History of doping and doping control. In: Thieme D, Hemmersbch $P$ (coordenadores). Doping in sports. Berlin: Springer; 2010. p. 1-24. 


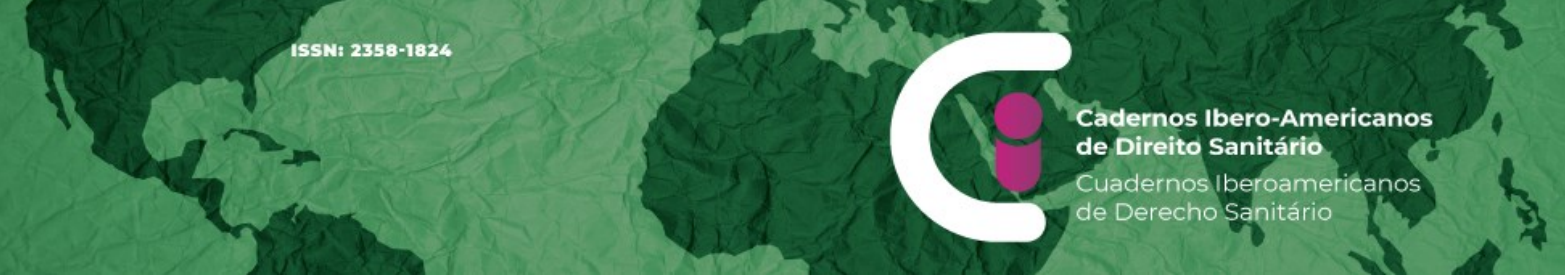

17. De Rose EH, Aquino Neto FR, Levy R. Informações sobre o uso de medicamentos no esporte [Internet]. 9a ed. Rio de Janeiro: COB; 2010 [acesso em 17.ago.2019]. Disponível em: http://www.apbmx.com.br/_upload/repository/Livreto_doping_2010.pdf

18. Conselho Federal de Medicina. Medicamentos e suplementos nos exercícios e esportes: dopagem e antidopagem, orientações de uso, riscos à saúde, responsabilidade profissional [Internet]. Brasília: CFM, 2018 [acesso em 03.set.2019]. Disponível em: http://www.cbc.esp.br/img/governanca/medicina_esporte.pdf

19. Leite A. Três razões para não criminalizar o doping desportivo. Carta Forense [Internet]. 02 Dez 2011 [acesso em 22.ago.2019]. Disponível em:

https://www.cartaforense.com.br/conteudo/colunas/tres-razoes-para-nao-criminalizar-odoping-desportivo/7997

20. Petibois C. Des responsables du sport face au dopagem. Les cas du cyclisme, rugby, de la natation et du surf. Paris: L'Hamattan; 1988. p. 20.

21. Kullok ALB. Doping e manipulação genética: uma perspectiva jurídico-criminal [Internet]. Comitê Olímpico de Portugal. Grupo de Pesquisa e Desenvolvimento Esportivo. 11 nov 2015 [acesso em 26.jul.2020]. Disponível em:

http://formacao.comiteolimpicoportugal.pt/Publicacoes/COP_PFO_EDGD/file013.pdf

22. World Anti-doping Agency. Code [Internet]. Wada; 2015 [acesso em 26.jul.2020]. Disponível em: https://www.wada-ama.org/sites/default/files/resources/files/wada-2015world-anti-doping-code.pdf

23. The International Federation of Sports Medicine. Statement on doping in sport [Internet]. [s. d] [acesso em 26.jul.2020]. Disponível em: https://www.fims.org/files/4414/2056/2561/PS13-Statement-on-Doping-in-Sport.pdf

24. Grandjean AC. Diets of elite athletes: has the discipline of sports nutrition made an impact? The journal of nutrition [Internet]. May 1997 [acesso em 26.jul.2020];127(5):874S877S. Disponível em: https://academic.oup.com/jn/article/127/5/874S/4724166

25. Harris HA. Nutrition and physical performance. The diet of Greek athletes [Internet]. 12 mar. 1966 [acesso em 26.jul.2020]. Disponível em:

https://www.cambridge.org/core/services/aop-cambridgecore/content/view/S0029665166000235

26. Costill DL. Carbohydrates for exercise: dietary demands for optimal performance. Int J Sports Med. Feb 1988;9(1):1-18.

27. Castanho GKF. Fatores motivacionais para o consumo de suplementos nutricionais por praticantes de exercícios físicos. [Tese de doutorado]. Campinas: UNICAMP; 2017 [acesso em 26.jul.2020]. 89 fls. Disponível em:

http://repositorio.unicamp.br/jspui/bitstream/REPOSIP/330689/1/Castanho_GabrielaKaiserF ullin_D.pdf 


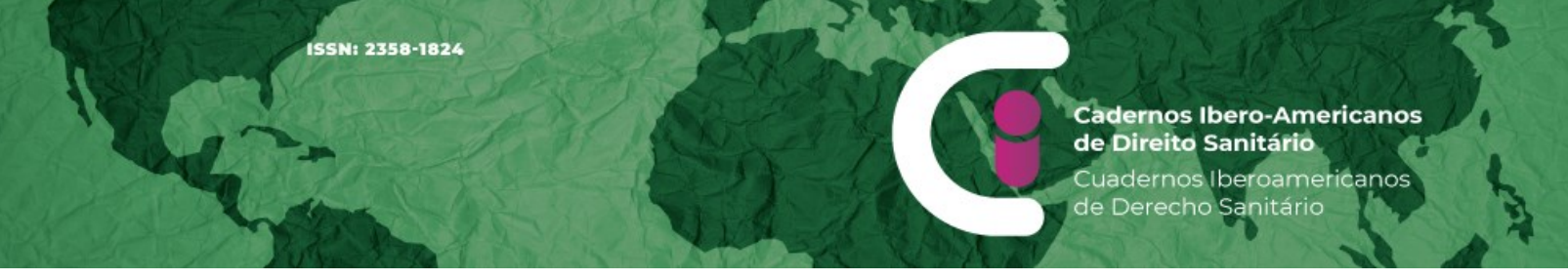

39. Lima e Feilgelson Advogados. Informe: requisitos sanitários para suplementos alimentares (Resoluções da Diretoria Colegiada da Anvisa $n^{\circ}$ 239/2018, 240/2018, 241/2018, 242/2018, 243/2018 e Instrução Normativa n² 28/2018) [Internet]. [s.d.] [acesso em 5.set.2019]. Disponível em: https://limafeigelson.com.br/ weblf/wpcontent/uploads/2018/08/Informe-ANVISA-Suplementos-Alimentares.pdf

40. Maia LE. Anvisa avançou em temas relevantes e se reestruturou. Consultor Jurídico [Internet]. 08 jan 2019 [acesso em 26.jul.2020]. Disponível em:

https://www.conjur.com.br/2019-jan-08/layla-maia-anvisa-avancou-temas-relevantesreestruturou

41. Anvisa. Suplementos alimentares [Internet]. 13 ago 2019 [acesso em 26.jul.2020]. Disponível em: http://portal.anvisa.gov.br/suplementos-alimentares

42. Anvisa divulga novas normas para suplementos alimentares. Acritica [Internet]. 30 mai 2019 [acesso em 04.set.2019]. Disponível em: https://www.acritica.com/channels/ cotidiano/news/anvisa-divulga-novas-normas-para-suplementos-alimentares

43. Andrade LA, Braz VG, Nunes APO, Velutto JN, Mendes RR. Consumo de suplementos alimentares por clientes de uma clínica de nutrição esportiva de São Paulo. Rev. Bras. Ci. e Mov 2012 [acesso em 26.jul.2020];20(3):27-36. Disponível em:

https://bdtd.ucb.br/index.php/RBCM/article/viewFile/3298/2266

44. Mantovani CC, Santos MF, Yonamine M. Suplementos nutricionais, hormônios e o controle da dopagem no esporte. Biotecnologia aplicada à Agro\&Indústria [Internet]. 2017 [acesso em 29.ago.2019];p. 775-814. Disponível em:

https://www.researchgate.net/publication/313492889_Suplementos_nutricionais_hormonios _e_o_controle_da_dopagem_no_esporte

45. Agência Mundial Antidopagem. Suplementos nutricionais e doping. Diário de Notícias [Internet]. 01 abr 2009 [acesso em 05.set.2019]. Disponível em:

https://www.dn.pt/desporto/antidoping/faq/ nutricao/interior/suplementos-nutricionais-edoping-1218510.html

46. Van Thuyne W, Van Eenoo P, Delbeke FT. Nutritional supplements: prevalence of use and contamination with doping agents. Nutrition Research Reviews [Internet]. 2006 [acesso em 26.jul.2020];19:147-58. Disponível em: https://www.ncbi.nlm.nih.gov/pubmed/19079882

47. Farah R. A responsabilidade objetiva do atleta em caso de doping. Direitonet [Internet]. 2005 [acesso em 26.jul.2020]. Disponível em:

https://www.direitonet.com.br/artigos/exibir/2205/A-responsabilidade-objetiva-do-atleta-emcaso-de-doping

48. Basualdo CRC, Prado DHS, Kondo M. Não existe pílula mágica. Revista Viver [Internet]. São Paulo: Hospital Sírio-Libanês. $5^{a}$ ed. 2014 [acesso em 03.set.2019]. Disponível em: https://www.hospitalsiriolibanes.org.br/institucional/ publicacoes/Publicacoes/revista-viver-edicao-5.pdf 
